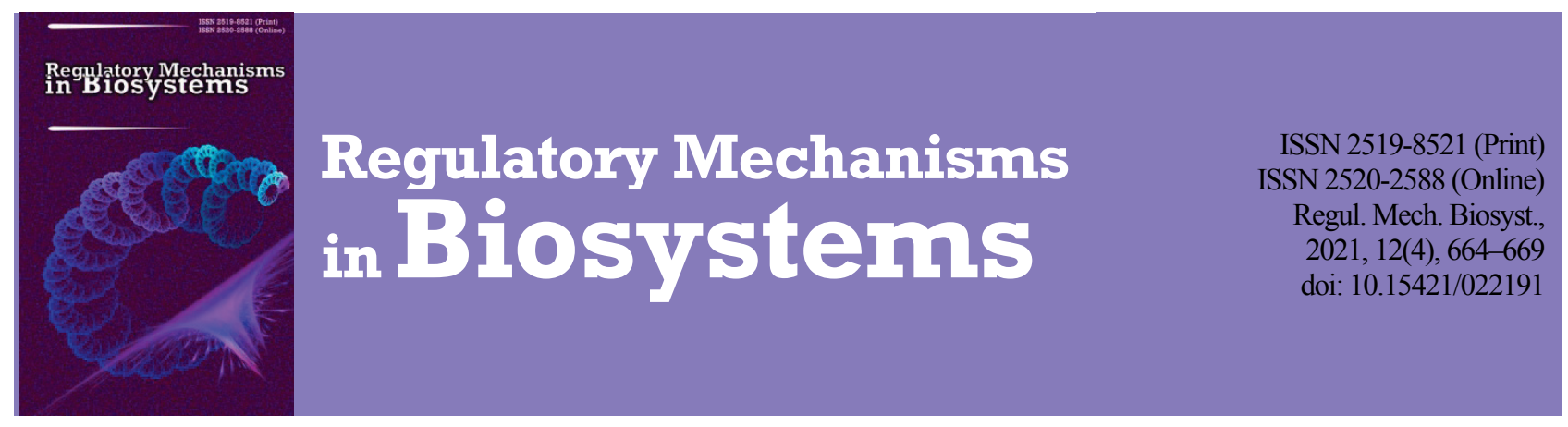

\title{
Biological responses in Musca domestica to fipronil and chlorfenapyr exposures
}

\author{
P. A. Shumilova, N. A. Sennikova, E. A. Silivanova, M. A. Levchenko \\ All-Russian Scientific Research Institute of Veterinary Entomology and Arachnology - Branch of Federal State Institution Federal \\ Research Centre Tyumen Scientific Centre of Siberian Branch of the Russian Academy of Sciences, Tyumen, Russian Federation
}

Article info

Received 25.09.2021

Received in revised form 18.10 .2021

Accepted 20.10.2021

All-Russian Scientific Research Institute of Veterinary Entomology and Arachnology - Branch of Federal State Institution Federal Research Centre Tyumen Scientific Centre of Siberian Branch of the Russian Academy of Sciences, Institutskaya st. 2, Tyumen, 625041, Russian Federation.

Tel.: +7-345-225-85-58 E-mail:easylva@gmail.com
Shumilova, P. A., Sennikova, N. A., Silivanova, E. A., \& Levchenko, M. A. (2021). Biological responses in Musca domestica to fipronil and chlorfenapyr exposures. Regulatory Mechanisms in Biosystems, 12(4), 664-669. doi:10.15421/022191

Insect populations exist under acute and chronic exposures to lethal and sublethal insecticide concentrations. Among the sublethal effects of insecticides on insects are reductions in life span, development rates, population growth, fertility, fecundity, changes in sex ratio, deformities, changes in behaviour, feeding, searching, and oviposition. These effects may differ depending on the modes of action of insecticides, their doses, and developmental stage of application. This study evaluated the life-history parameters in Musca domestica Linnaeus, 1758 (Diptera:Muscidae) strains that were exposed to two insecticides (fipronil and chlorfenapyr) with different modes of action at sublethal concentrations in each generation up to tenth. Two approaches to each insecticide's exposure were used in this study, particularly in one approach, only adults $M$. domestica were exposed to fipronil or chlorfenapyr and in another approach, only larvae were exposed to each insecticide. The susceptibility of adult flies to these insecticides was assessed by resistance ratio based on results of non-choice feeding bioassays. Fipronil exposure at the sublethal concentration in each generation did not affect the susceptibility of adult $M$. domestica (in the tenth generation) to fipronil. The resistance ratio values revealed tolerance to chlorfenapyr in adults of $M$. domestica strains that were exposed to this insecticide, independent of the approach used to insecticide exposure. Most of the life-history parameters (such as durations of separate developmental stages, the emergence duration, the adult emergence ratio, the female ratio, and the number of eggs per female per day) of the second, fourth, sixth, eighth, and tenth generations of the insecticide-exposed strains were similar to those of the control strain. At the same time, the sublethal effects of both insecticides fipronil and chlorfenapyr prolonged the larval duration (1.63-2.22 times) and the number of days from egg to adult (1.18-1.39 times) compared to the control strain. Further studies are needed to investigate a possible genetic variability in $M$. domestica in response to exposure of parental generation to sublethal doses of fipronil and chlorfenapyr.

Keywords: life cycle parameters; response to insecticides; sublethal effects; transgenerational insecticidal effects; Diptera.

\section{Introduction}

The application of insecticides and acaricides is considered one of the most effective and commonly used tools for the management of pest and parasite arthropods in agriculture, veterinary medicine, and human medicine. Insecticides, including the active ingredient compounds and the formulation aggregates, are subject to various abiotic and biotic processes in the environment (de França et al., 2017; Müller 2018). As a result, insecticides degrade over time and the insecticide concentrations change at a spatial and temporal scale (Lalouette et al., 2016; de França et al., 2017; Müller, 2018). Thus, insect populations exist under acute and chronic exposures to lethal and sublethal insecticide concentrations and should respond to them. Insects and mites have the ability to develop insecticide resistance as a response to insecticide exposure. Currently, more than 600 species of insects and mites have developed resistance to at least one insecticide (Sparks et al., 2020). Insecticides are able to impact subsequent generations of arthropods due to chronic and sublethal effects at the physiological and behavioural level and cause change in different parameters such as the lifespan and durations of certain developmental stages, weight, fertility, feeding, egg-laying, etc. (Farooq \& Freed, 2018; Kozak et al., 2020). Müller (2018) reviewed new findings on effects of sublethal insecticide concentrations on various life-history and demographic traits of different insect species. The study of chronic and sublethal effects of insecticide exposures and their species features is useful in terms of the development of new means and approaches to control of harmful insects, as well as for preventing and overcoming insecticidal resistance.
Most conventional insecticides are neurotoxins that disturb the transmission of neuronal impulses in nerve. For instance, phenylpyrazole fipronil which belongs to antagonists of $\gamma$-aminobutyric acid (GABA) gated chloride channels (Casida \& Durkin, 2013; Sparks et al., 2020) leads to overstimulation of the nervous system. In Russia, fipronil is used to protect plants from arthropod pests in agriculture, and as toxic baits against cockroaches in the sanitation field, and as veterinary drugs against arthropod ectoparasites of pets. Published data give evidence about fipronil resistance in insect field populations, for example, in Colorado potato beetle Leptinotarsa decemlineata Say, 1824 (Coleoptera, Chrisomelidae) (Leontieva et al., 2016) and German cockroach Blattella germanica Linnaeus, 1767 (Blattidae, Ectobiidae) (Eremina et al., 2016). According to some studies (Kristensen et al., 2004; Abbas et al., 2016), the development of resistance to fipronil is possible in $M$. domestica under its intensive use. As opposed to neurotoxins, chlorfenapyr from the group of arylpyrroles is an uncoupler of oxidative phosphorylation (Sparks et al., 2020). In insects, under the effects of cytochrome $\mathrm{P}_{450}$ monooxygenases, chlorfenapyr is converted into a chemical compound that can uncouple oxidative phosphorylation in the mitochondria. Chlorfenapyr has different kinds of activities, it is characterized mainly by contact and some intestinal activity, is an insecticide, nematocide and acaricide (Eremina, 2017). Chlorfenapyr is effectively used as a non-repellent insecticide against synanthropic insects such as cockroaches, bed bugs, termites, ants, biting flies and mosquitoes (Ameen et al., 2000; Guglielmone et al., 2000; Buczkowski et al., 2005; Rust \& Saran, 2006; N'Guessan et al., 2007; Romero et al., 2010), including malaria vectors (Rust \& Saran, 2006; N'Guessan et al., 2007, 2009). 
Insecticidal baits containing chlorfenapyr are used in livestock facilities to manage non-biting flies (Levchenko \& Silivanova, 2015). The appearance of pest populations resistant to chlorfenapyr has been noted in countries where chlorfenapyr-based formulations are used for plant protection (Qayyum et al., 2015; Ullah et al., 2016; Zhang et al., 2016).

The house fly, Musca domestica Linnaeus, 1758, (Diptera, Muscidae), is a globally distributed synanthropic insect that has veterinary and medical significance. M. domestica is a carrier of more than 100 pathogens that may cause diseases in human and animals and significant economic damage to livestock and poultry (Byford et al., 1992; Förster et al., 2007). According to the literature data the house fly has been found to be resistant to 62 insecticide active ingredients (Zhu et al., 2016). The purpose of this study was to evaluate some biological parameters of the $M$. domestica laboratory strain in response to exposure to fipronil and chlorfenapyr.

\section{Materials and methods}

The current study was performed using two industrial insecticides from different chemical classes fipronil (99\%, King Quenson Industry Group Ltd, China), and chlorfenapyr ( $99 \%$, Chengdu Newsun Biochemistry Co. Ltd, China) as active ingredients and acetone (Sibtechnology Co., Russian Federation) as a solvent.

The object of the study was house flies $M$. domestica. The laboratory strain (Lab) of $M$. domestica was reared at $26-28{ }^{\circ} \mathrm{C}$, at $50-60 \%$ relative humidity (RH), and at a 12:12 light:dark period in the insectarium. The adult flies were kept in metal cages of a size of $25 \times 25 \times 25 \mathrm{~cm}$, covered with a fine mesh. Rearing cages were supplied with water (cotton wicks lowered in cups filled with water) and glucose and milk powder (1:1 by weight). The breeding medium for rearing larvae consisted of wheat bran $200 \mathrm{~g}$, water $400 \mathrm{~mL}$, and Baker's yeast $10 \mathrm{~g}$. Larvae were kept in glass containers with the breeding medium. The containers were covered with gauze; as the larvae developed, the medium was added and periodically mixed for aeration.

One part of the Lab-strain was selected to be exposed to fipronil for ten generations. These were divided in turn into two groups; adults exposed to the insecticide, marked as the fipronil-selected strain A (FipA), and larvae exposed to the insecticide, marked as the fipronil-selected strain L (FipL). The other part of the Lab-strain was selected to be exposed to chlorfenapyr for ten generations, of which the adult group was marked as the chlorfenapyr-selected strain A (ChlA) and larvae marked as the chlorfenapyr-selected strain L (ChlL).

In the group adults exposed to the insecticide, starving three-five dayold adults (both males and females) were exposed to fipronil or chlorfenapyr by feeding them (for 24 hours) sugar that was treated with acetone solutions of the relevant insecticide. After that, the sugar was replaced with standard food, and the surviving flies were used as parents for the next generation. The selection concentrations of fipronil were $0.0001 \%$ in a volume of $1 \mathrm{~mL}$ per $\mathrm{g}$ of sugar for G1-G10 generations for the FipA strain, and the selection concentrations of chlorfenapyr were $0.001 \%$ and $0.002 \%$ in a volume of $1 \mathrm{~mL}$ per $\mathrm{g}$ of sugar for G1-G4 generations and G5-G10 generations respectively for the ChlA strain.

In the group larvae exposed to the insecticide, three hundred 3st instar larvae were exposed to fipronil or chlorfenapyr by contact with insecticides in the breeding medium that was mixed with shavings soaked with water and acetone solutions of insecticides. The emerging adult flies were used as parents for the next generation. The selection concentrations of fipronil were $0.001 \%$ and $0.0005 \%$ in a volume of $10 \mathrm{~mL}$ per $40 \mathrm{~g}$ of medium for G1-G3 generations and G4-G10 generations respectively. The selection concentrations of chlorfenapyr were $0.01 \%$ and $0.005 \%$ in a volume of $10 \mathrm{~mL}$ per $40 \mathrm{~g}$ of medium for G1-G7 generations and G8G10 generations respectively.

The toxicity of fipronil and chlorfenapyr to $M$. domestica adults was evaluated by a no-choice feeding test. Flies starved for 12 hours prior to the experiment. The sugar $(0.1 \mathrm{~g})$ was placed in glass cups and treated with $30 \mu \mathrm{L}$ acetone solutions of fipronil or chlorfenapyr at 5-6 concentrations. Cups with the sugar treated with pure acetone (without insecticide) and with no-treated sugar were used as the control. After the acetone evaporated, ten flies were placed into each cup. The cups were sealed with mesh pistons from the top and supplied with water drinkers. The mortality was recorded after 48 hours and immobilized flies were considered dead. The control tests and tests with each concentration of fipronil or chlorfenapyr were replicated at least three times.

The study of life-history and morphological parameters was conducted for the Lab strain and G2, G4, G6, G8, and G10 generations of the FipA, FipL, ChlA, and ChlL strains of $M$. domestica. One hundred second instar larvae were randomly collected from each population and then placed into plastic cups with the breeding medium described above. This was done at least three times for each population. The life-history parameters were recorded in each population such as the development time from eggs to adults, the time from eggs to pupae, the pupal duration, the pupation ratio, the emergence duration, the adult emergence ratio, and the female ratio. The new emergent flies were provided the egg-laying medium that was viewed daily for eggs. The eggs were counted with the aid of a hand lens to calculate the number of eggs per female per day. The individual weights were assessed in each population such as larval weight (ten second instar larvae for each replicate), pupal weight (ten pupae within 48 hours of their formation for each replicate), weight of 3 5-days old female and males (ten flies for each replicate).

The dose-response mortality in the no-choice feeding tests was analyzed by probit regression analysis to calculate lethal concentrations for $50 \%\left(\mathrm{LC}_{50}\right)$ mortality for $95 \%$ confidence interval $(\mathrm{CI})$ using the SPSS Statistics 22 software. The difference between $\mathrm{LC}_{50}$ values of insecticides in the Lad strain and the FipA, FipL, ChlA, and ChlL strains was considered as statistically significant when their $95 \%$ CIs did not overlap. The resistance ratio (RR) was calculated by dividing the $\mathrm{LC}_{50}$ value of the certain selected strain by the $\mathrm{LC}_{50}$ of the Lab strain. Data from life history and morphological parameter testing were analyzed using analytical software SPSS Statistics 28, and the results included means and standard deviation. The statistical significance of differences between parameters was evaluated by ANOVA and Tukey test when the Lab and the selected strains were compared.

\section{Results}

In our study bioassays showed that the susceptibilities of adults M. domestica to fipronil in third/fourth generations and in the tenth generation of the FipA strain were the same as in the Lab strain (Table 1). The susceptibility of adults $M$. domestica to fipronil in fifth generation and in tenth generation of the FipL strain was slightly lower than in the Lab strain through that difference was not statistically significant.

Toxicity of chlorfenapyr to adults $M$. domestica of the ChlA (tenth generation) and the ChlL (sixth generation) strain decreased and the $\mathrm{LC}_{50}$ values of chlorfenapyr for the Lab and two Chl strains statistically significantly differed because their $95 \%$ confidence intervals did not overlap. The ChlA strain of M. domestica in tenth generation and the ChlL strain in sixth generation reached a resistance ratio of 3.62 and 3.26 respectively and developed tolerance to chlorfenapyr (Table 1).

\section{Table 1}

Toxicity of fipronil and chlorfenapyr to adult Musca domestica of insecticide-selected and un-selected (Lab) strains $(\mathrm{N}=180)$

\begin{tabular}{ccccc}
\hline \multirow{2}{*}{ Strain } & Generation & $\begin{array}{c}\mathrm{LC}_{50}(95 \% \mathrm{CI}), \\
\mu \mathrm{g} \text { per g of sugar }\end{array}$ & Slope $(\mathrm{x} \pm \mathrm{SE})$ & $\mathrm{RR}(95 \% \mathrm{Cl})$ \\
\hline \multicolumn{5}{c}{ Fipronil } \\
\hline Lab & - & $0.75(0.60-0.90)$ & $2.701 \pm 0.300$ & - \\
FipA & 3 and 4 & $0.65(0.48-0.90)$ & $4.733 \pm 1.283$ & $0.87(0.80-1.00)$ \\
& 10 & $0.54(0.45-0.68)$ & $3.657 \pm 0.603$ & $0.72(0.75-0.76)$ \\
FipL & 5 & $1.22(0.60-2.11)$ & $1.908 \pm 0.513$ & $1.63(1.00-2.34)$ \\
& 10 & $0.97(0.39-2.49)$ & $1.139 \pm 0.242$ & $1.29(0.65-2.77)$ \\
\hline \multicolumn{5}{c}{ Chlorfenapyr } \\
\hline Lab & - & $21.60(18.00-25.80)$ & $2.606 \pm 0.080$ & - \\
ChlA & 3 & $21.00(11.10-40.80)$ & $1.708 \pm 0.113$ & $0.97(0.62-1.58)$ \\
& 10 & $78.15(54.93-101.61)$ & $1.821 \pm 0.122$ & $3.62(3.05-3.94)$ \\
ChlL & 6 & $70.41(37.08-128.85)$ & $2.034 \pm 0.463$ & $3.26(2.06-4.99)$ \\
& 10 & $52.92(1.20-197.31)$ & $1.793 \pm 0.677$ & $2.45(0.07-7.65)$ \\
\hline
\end{tabular}

Notes: N - number of flies; FipA - adults only were exposed to fipronil; FipL - larvae only were exposed to fipronil; ChlA - adults only were exposed to chlofenapyr; ChlL larvae only were exposed to chlorfenapyr; $\mathrm{LC}_{50}(95 \% \mathrm{Cl})$ - lethal concentration for $50 \%$ mortality ( $95 \%$ confidence interval); $\mathrm{RR}$ - resistance ratio was calculated by dividing the $\mathrm{LC}_{50}$ value of the selected strain (Fip or Chl) by the $\mathrm{LC}_{50}$ of the $\mathrm{Lab}$ strain. 
Most of the life-history parameters of the second, fourth, sixth, eighth, and tenth generations of the FipA, FipL, ChlA, and ChlL strains were similar to those of the Lab strain (Tables 2-5). The average mean weight of one specimen varied from 6.85 to $17.67 \mathrm{mg}$ at the stage of larva of second-third instar, $10.56-16.55 \mathrm{mg}$ at the pupal stage, $11.63-18.60 \mathrm{mg}$ at the stage of 3-5 days-old female, and $6.91-11.03 \mathrm{mg}$ at the stage of $3-$ 5-days old male (Table 6).

Based on the ANOVA test, we observed the statistically significant difference between the Lab and the FipA strains in larval duration $(\mathrm{P}=$ $0.001)$ and development time from eggs to adults $(\mathrm{P}=0.001$, Table 2$)$. The Tukey test detected statistically significant prolongation of the larval stage in the second, fourth, and tenth generations of the FipA strain by 1.70 times $(\mathrm{P}=0.038), 2.16$ times $(\mathrm{P}=0.001)$, and 1.70 times $(\mathrm{P}=0.038)$ compared to the Lab strain (Table 2$)$.

Pupal durations in the FipA generations were shorter than in the Lab strain $(\mathrm{P}=0.121)$ and this developmental stage lasted 1.91 times less $(\mathrm{P}=0.156)$ in the sixth generation of the FipA strain compared to the Lab strain. The total number of days from eggs to adults was statistically significantly $1.28(\mathrm{P}=0.024), 1.39(\mathrm{P}=0.001)$, and $1.18(\mathrm{P}=0.256)$ times more in the second, fourth, and tenth generations of the FipA strain than in the Lab strain respectively. Males of M. domestica weighed $40.9 \%(\mathrm{P}=0.032)$ and $37.1-41.1 \%$ less in the $\mathrm{Lab}$ strain and in certain generations of FipA strains compared to females (Table 6).

Table 2

Life-history parameters of fipronil-selected (FipA, adults only were exposed to fipronil) and un-selected (Lab) strains of M. domestica (x $\pm \mathrm{SD})$

\begin{tabular}{|c|c|c|c|c|c|c|c|c|c|}
\hline $\begin{array}{c}\text { Strain/ } \\
\text { generation }\end{array}$ & $\begin{array}{c}\text { Larval } \\
\text { duration, days }\end{array}$ & $\begin{array}{c}\text { Pupal } \\
\text { duration, days }\end{array}$ & $\begin{array}{l}\text { Adult's emergence } \\
\text { duration, days }\end{array}$ & $\begin{array}{l}\text { Development time from } \\
\text { eggs to adults, days }\end{array}$ & $\begin{array}{c}\text { Percent } \\
\text { pupation, } \%\end{array}$ & $\begin{array}{c}\text { Adult } \\
\text { emergence, } \%\end{array}$ & $\begin{array}{l}\text { Female } \\
\text { ratio, } \%\end{array}$ & $\begin{array}{l}\text { Number of } \\
\text { egg-laying per } \\
\text { female per day }\end{array}$ & $\begin{array}{l}\text { Number } \\
\text { of eggs per } \\
\text { egg-laying }\end{array}$ \\
\hline $\mathrm{Lab}$ & $5.10 \pm 1.10$ & $5.10 \pm 1.91$ & $4.00 \pm 1.50$ & $14.36 \pm 1.97$ & $84.28 \pm 15.92$ & $59.40 \pm 11.57$ & $54.78 \pm 7.38$ & $0.13 \pm 0.10$ & $60.14 \pm 15.85$ \\
\hline \multicolumn{10}{|c|}{ FipA } \\
\hline G2 & $8.67 \pm 0.58^{* \uparrow}$ & $4.33 \pm 1.15$ & $4.33 \pm 0.58$ & $18.33 \pm 1.15^{* \uparrow}$ & $64.00 \pm 15.62$ & $64.67 \pm 7.57$ & $53.00 \pm 3.00$ & nd & nd \\
\hline G4 & $11.00 \pm 3.61^{* \uparrow}$ & $3.67 \pm 0.58$ & $4.33 \pm 0.58$ & $20.00 \pm 3.61^{* \uparrow}$ & $81.00 \pm 4.36$ & $72.00 \pm 23.90$ & $53.67 \pm 2.08$ & $0.089 \pm 0.042$ & $60.00 \pm 17.32$ \\
\hline G6 & $5.33 \pm 1.15$ & $2.67 \pm 0.58$ & $3.33 \pm 1.15$ & $12.33 \pm 0.58$ & $93.67 \pm 2.31$ & $74.33 \pm 8.62$ & $53.40 \pm 9.75$ & $0.083 \pm 0.032$ & $47.33 \pm 3.51$ \\
\hline G8 & $8.33 \pm 1.15$ & $3.00 \pm 1.00$ & $3.67 \pm 0.58$ & $15.33 \pm 1.15$ & $88.33 \pm 11.06$ & $40.67 \pm 13.05$ & $51.00 \pm 1.73$ & $0.073 \pm 0.045$ & $57.00 \pm 10.58$ \\
\hline G10 & $8.67 \pm 2.08^{* \uparrow}$ & $3.67 \pm 0.58$ & $4.00 \pm 1.00$ & $17.00 \pm 1.00$ & $83.00 \pm 6.08$ & $56.00 \pm 11.79$ & $55.10 \pm 21.37$ & $0.113 \pm 0.049$ & $67.33 \pm 13.20$ \\
\hline $\mathrm{P}$ & 0.001 & 0.121 & 0.885 & 0.001 & 0.141 & 0.069 & 0.993 & 0.798 & 0.541 \\
\hline
\end{tabular}

Notes: SD - standard deviation; nd - not determined; $\mathrm{P}$ - p-value according to ANOVA test; ${ }^{*}$ - statistically significant difference $\left({ }^{\uparrow}\right.$ - an increase; ${ }^{\downarrow}$-a decrease) compared to Lab strain according to Tukey test $(\mathrm{P}<0.05)$.

Table 3

Life-history parameters of fipronil-selected (FipL, larvae only were exposed to fipronil) and un-selected (Lab) strains of M. domestica $(\mathrm{x} \pm \mathrm{SD})$

\begin{tabular}{|c|c|c|c|c|c|c|c|c|c|}
\hline $\begin{array}{c}\text { Strain/ } \\
\text { generation }\end{array}$ & $\begin{array}{c}\text { Larval } \\
\text { duration, days }\end{array}$ & $\begin{array}{c}\text { Pupal } \\
\text { duration, days }\end{array}$ & $\begin{array}{c}\text { Adult's emergence } \\
\text { duration, days }\end{array}$ & $\begin{array}{l}\text { Development time from } \\
\text { eggs to adults, days }\end{array}$ & $\begin{array}{c}\text { Percent } \\
\text { pupation, } \%\end{array}$ & $\begin{array}{c}\text { Adult } \\
\text { emergence, } \%\end{array}$ & $\begin{array}{l}\text { Female } \\
\text { ratio, } \%\end{array}$ & $\begin{array}{c}\text { Number of } \\
\text { egg-laying per } \\
\text { female per day }\end{array}$ & $\begin{array}{c}\text { Number of } \\
\text { eggs per egg- } \\
\text { laying }\end{array}$ \\
\hline Lab & $5.10 \pm 1.10$ & $5.10 \pm 1.91$ & $4.00 \pm 1.50$ & $14.36 \pm 1.97$ & $84.28 \pm 15.92$ & $59.40 \pm 11.57$ & $54.78 \pm 7.38$ & $0.13 \pm 0.10$ & $60.14 \pm 15.85$ \\
\hline \multicolumn{10}{|c|}{ FipL } \\
\hline G2 & nd & nd & nd & nd & nd & nd & nd & nd & nd \\
\hline G4 & $8.33 \pm 2.52^{* \uparrow}$ & $3.00 \pm 1.00$ & $7.33 \pm 1.15^{* \uparrow}$ & $19.67 \pm 2.08^{* \uparrow}$ & $72.00 \pm 2.00$ & $52.67 \pm 1.53$ & $53.30 \pm 16.87$ & $0.180 \pm 0.071$ & $42.50 \pm 10.61$ \\
\hline G6 & $7.33 \pm 2.31$ & $3.33 \pm 1.15$ & $7.67 \pm 2.89^{* \uparrow}$ & $19.67 \pm 4.62^{* \uparrow}$ & $90.67 \pm 6.03$ & $56.00 \pm 21.79$ & $65.00 \pm 5.20$ & $0.247 \pm 0.204$ & $50.67 \pm 2.08$ \\
\hline G8 & $8.33 \pm 0.58^{* \uparrow}$ & $2.67 \pm 0.58$ & $6.67 \pm 0.58$ & $18.00 \pm 1.00$ & $97.00 \pm 3.61$ & $80.67 \pm 16.26$ & $51.67 \pm 1.16$ & $0.100 \pm 0.050$ & $53.00 \pm 8.00$ \\
\hline G10 & $8.67 \pm 0.58^{* \uparrow}$ & $3.00 \pm 0.00$ & $7.00 \pm 1.00$ & $18.67 \pm 0.58^{* \uparrow}$ & $95.33 \pm 3.51$ & $64.33 \pm 26.84$ & $54.67 \pm 10.97$ & $0.056 \pm 0.007$ & $77.33 \pm 9.50$ \\
\hline $\mathrm{P}$ & 0.002 & 0.063 & 0.006 & 0.001 & 0.094 & 0.288 & 0.421 & 0.299 & 0.059 \\
\hline
\end{tabular}

Notes: see Table 3.

Life-history parameters of the FipL strain are represented in Table 3. According to the ANOVA test, values of three parameters (namely, larval duration, adult's emergence duration, and development time) statistically significantly varied in the generations of the FipL strain. The stage of larva lasted statistically significantly longer by 1.63 times in the fourth $(\mathrm{P}=$ $0.025)$ and the eighth $(P=0.005)$ generations, and 1.70 times $(P=0.012)$ in the tenth generations of the FipL strain than in the Lab strain. In contrast, the stage of pupa lasted 1.91 times less in the eighth generation of the FipL strain than in the Lab strain $(\mathrm{P}=0.146)$. Also, we noted an increase in adult emergence durations in the FipL strain and this parameter was
1.83 times $(\mathrm{P}=0.041)$ and 1.92 times $(\mathrm{P}=0.022)$ more in the fourth and sixth generations respectively than in the Lab strain. As the Tukey test showed, the development times from eggs to adults were statistically significant longer by 1.37 times $(\mathrm{P}=0.003)$ in the fourth and the sixth generations and by 1.30 times $(P=0.023)$ in the tenth generations of the FipL strain compared to the Lab strain value. According to ANOVA analysis, larval weights in the FipL strain varied statistically significantly $(\mathrm{P}=0.039)$. Males of $M$. domestica in the sixth and tenth generations of FipL strains weighed $48.3 \%(\mathrm{P}=0.088)$ and $42.6 \%(\mathrm{P}=0.018)$ respectively less compared to females (Table 6).

Table 4

Life-history parameters of chlorfenapyr-selected (ChlA, adults only were exposed to chlorfenapyr) and un-selected (Lab) strains of M. domestica (x $\pm \mathrm{SD})$

\begin{tabular}{|c|c|c|c|c|c|c|c|c|c|}
\hline $\begin{array}{c}\text { Strain/ } \\
\text { generation }\end{array}$ & $\begin{array}{c}\text { Larval } \\
\text { duration, days }\end{array}$ & $\begin{array}{c}\text { Pupal } \\
\text { duration, days }\end{array}$ & $\begin{array}{l}\text { Adult's emergence } \\
\text { duration, days }\end{array}$ & $\begin{array}{l}\text { Development time } \\
\text { from eggs to adults, } \\
\text { days }\end{array}$ & $\begin{array}{c}\text { Percent } \\
\text { pupation, } \%\end{array}$ & $\begin{array}{c}\text { Adult } \\
\text { emergence, } \%\end{array}$ & $\begin{array}{l}\text { Female } \\
\text { ratio, } \%\end{array}$ & $\begin{array}{c}\text { Number of } \\
\text { egg-laying per } \\
\text { female per day }\end{array}$ & $\begin{array}{l}\text { Number of } \\
\text { eggs per egg- } \\
\text { laying }\end{array}$ \\
\hline $\mathrm{Lab}$ & $5.10 \pm 1.10$ & $5.10 \pm 1.91$ & $4.00 \pm 1.50$ & $14.36 \pm 1.97$ & $84.28 \pm 15.92$ & $59.40 \pm 11.57$ & $54.78 \pm 7.38$ & $0.13 \pm 0.10$ & $60.14 \pm 15.85$ \\
\hline \multicolumn{10}{|c|}{ ChlA } \\
\hline G2 & $8.00 \pm 1.73$ & $6.67 \pm 0.58$ & $4.33 \pm 1.15$ & $17.33 \pm 1.53$ & $81.00 \pm 5.57$ & $60.50 \pm 6.36^{\#}$ & $51.96 \pm 14.38^{\#}$ & $0.08 \pm 0.02^{\#}$ & $56.25 \pm 13.92^{\#}$ \\
\hline G4 & $11.33 \pm 2.31^{* \uparrow}$ & $3.33 \pm 0.58$ & $6.00 \pm 2.00$ & $20.00 \pm 2.65^{* \uparrow}$ & $92.33 \pm 5.13$ & $57.67 \pm 6.66$ & $48.90 \pm 4.59$ & $0.12 \pm 0.03$ & $43.47 \pm 10.24$ \\
\hline G6 & $4.67 \pm 2.89$ & $5.00 \pm 3.00$ & $5.00 \pm 1.00$ & $15.00 \pm 1.73$ & $81.67 \pm 15.04$ & $37.67 \pm 20.84$ & $52.00 \pm 7.00$ & $0.18 \pm 0.03$ & $51.66 \pm 18.86$ \\
\hline G8 & $5.67 \pm 0.58$ & $2.33 \pm 0.58$ & $4.00 \pm 0.00$ & $13.00 \pm 1.00$ & $96.67 \pm 1.53$ & $73.00 \pm 1.00$ & $59.90 \pm 8.03$ & $0.09 \pm 0.01$ & $44.43 \pm 7.17$ \\
\hline G10 & $8.67 \pm 0.58^{* \uparrow}$ & $3.33 \pm 0.58$ & $3.50 \pm 0.71$ & $15.00 \pm 0.00$ & $88.00 \pm 7.00$ & $41.33 \pm 2.08$ & $57.30 \pm 8.30$ & $0.10 \pm 0.04$ & $51.25 \pm 3.31$ \\
\hline $\mathrm{P}$ & 0.001 & 0.042 & 0.294 & 0.001 & 0.543 & 0.009 & 0.717 & 0.593 & 0.397 \\
\hline
\end{tabular}

Notes: SD - standard deviation; nd - not determined; $\mathrm{P}$ - p-value according to ANOVA test; ${ }^{*}$ - statistically significant difference $\left({ }^{\uparrow}\right.$ - an increase; ${ }^{\star}-$ a decrease) compared to Lab strain according to Tukey test $(\mathrm{P}<0.05) ;{ }^{\#}$ - results from first and second generations together. 
Table 5

Life-history parameters of chlorfenapyr-selected (ChlL, larvae only were exposed to chlorfenapyr) and un-selected (Lab) strains of M. domestica (x $\pm \mathrm{SD})$

\begin{tabular}{|c|c|c|c|c|c|c|c|c|c|}
\hline $\begin{array}{c}\text { Strain/ } \\
\text { generation }\end{array}$ & $\begin{array}{c}\text { Larval } \\
\text { duration, days }\end{array}$ & $\begin{array}{c}\text { Pupal } \\
\text { duration, days }\end{array}$ & $\begin{array}{l}\text { Adult's emergence } \\
\text { duration, days }\end{array}$ & $\begin{array}{l}\text { Development time } \\
\text { from eggs to adults, } \\
\text { days }\end{array}$ & $\begin{array}{c}\text { Percent } \\
\text { pupation, \% }\end{array}$ & $\begin{array}{c}\text { Adult } \\
\text { emergence, } \%\end{array}$ & $\begin{array}{l}\text { Female } \\
\text { ratio, \% }\end{array}$ & $\begin{array}{l}\text { Number of } \\
\text { egg-laying per } \\
\text { female per day }\end{array}$ & $\begin{array}{c}\text { Number of } \\
\text { eggs per egg- } \\
\text { laying }\end{array}$ \\
\hline $\mathrm{Lab}$ & $5.10 \pm 1.10$ & $5.10 \pm 1.91$ & $4.00 \pm 1.50$ & $14.36 \pm 1.97$ & $84.28 \pm 15.92$ & $59.40 \pm 11.57$ & $54.78 \pm 7.38$ & $0.13 \pm 0.10$ & $60.14 \pm 15.85$ \\
\hline \multicolumn{10}{|c|}{ ChlA } \\
\hline G2 & nd & nd & nd & nd & nd & nd & nd & nd & nd \\
\hline G4 & nd & nd & nd & nd & nd & nd & nd & nd & nd \\
\hline G6 & $6.67 \pm 1.53$ & $4.33 \pm 1.53$ & $4.33 \pm 0.58$ & $15.67 \pm 0.58$ & $86.67 \pm 4.73$ & $29.67 \pm 10.21^{* \downarrow}$ & $54.50 \pm 6.77$ & $0.227 \pm 0.178$ & $57.33 \pm 15.95$ \\
\hline G8 & $6.67 \pm 0.58$ & $3.33 \pm 0.58$ & $5.67 \pm 1.53$ & $16.33 \pm 0.58$ & $83.00 \pm 15.87$ & $52.00 \pm 20.00$ & $39.87 \pm 10.10$ & $0.175 \pm 0.064$ & $62.00 \pm 8.49$ \\
\hline G10 & $7.33 \pm 1.53^{* \uparrow}$ & $3.00 \pm 1.00$ & $7.67 \pm 2.89$ & $19.00 \pm 3.64^{* \uparrow}$ & $77.00 \pm 28.58$ & $48.67 \pm 10.02$ & $55.00 \pm 8.52$ & $0.157 \pm 0.051$ & $40.33 \pm 11.72$ \\
\hline $\mathrm{P}$ & 0.032 & 0.197 & 0.034 & 0.005 & 0.909 & 0.042 & 0.069 & 0.632 & 0.271 \\
\hline
\end{tabular}

Notes: see Table 2.

The ANOVA revealed the statistically significant difference between the Lab and the ChlA strains in larval duration $(\mathrm{P}=0.001)$, pupal duration $(\mathrm{P}=0.042)$, development time from eggs to adults $(\mathrm{P}=0.001)$, and adult emergence ( $\mathrm{P}=0.009$, Table 4). According to the Tukey test the larval duration increased by 2.22 times $(\mathrm{P}=0.001)$ and 1.70 times $(\mathrm{P}=0.025)$ in the fourth and tenth generations of the ChlA strain compared to that of Lab strain. Also, the number of days from egg to adult appearance was more by 1.39 times $(\mathrm{P}=0.001)$ in the fourth generation of the ChlA strain in comparison with the Lab strain. The ANOVA test showed the percent of adult emergence significantly varied $(\mathrm{P}=0.009)$, and the lowest value was in the sixth generation of the ChlA strain. There were no statistically significant changes with respect to duration of emergence, and female fecundity in the ChlA strain relative to the Lab one (Table 4). The ANOVA analysis showed statistically significant differences in the weight of one specimen at the larva stage between the Lab and the ChlA strains $(\mathrm{P}=$ 0.021). According to the Tukey test, the larval weight in the tenth generation of the ChlA strain decreased by $50.3 \%$ compared to that of Lab strain $(\mathrm{P}=0.074)$. Males of $M$. domestica in the even generations of ChlA strains weighed $38.6-43.0 \%$ less compared to females.

Results obtained for the ChlL strain are represented in Table 5. The statistically significant differences compared to the Lab strain were observed in a number of larval duration days $(\mathrm{P}=0.032)$, adult's emergence duration $(\mathrm{P}=0.034)$, in the number of days from eggs to adults $(\mathrm{P}=$ $0.005)$, and in percentage of adult emergence $(\mathrm{P}=0.042)$. In the tenth generation of the ChlL strain, the larval duration and the number of days from eggs to adults was more than in the Lab strain by 1.44 times $(\mathrm{P}=$ $0.051)$ and 1.32 times $(P=0.004)$ respectively. In the sixth generation of the ChlL strain, we noted the minimal value of the percentage of adult emergence (29.7\%) that was 2.00 times less than in the Lab strain $(\mathrm{P}=$ 0.027). Males of $M$. domestica in the sixth and tenth generations of ChIL strains weighed $43.0 \%(\mathrm{P}=0.102)$, and $46.7 \%(\mathrm{P}=0.065$, respectively $)$ less compared to females (Table 6).

\section{Discussion}

Müller (2018) highlighted that insecticides not only act on the targeted primary site, but also interact with secondary sites of action in insects. Such interaction may evoke sublethal reactions that interfere with the organism's survival and/or reproduction, affecting its (neuro)physiology, performance, behaviour, ecology and communication (Müller, 2018). Taking into account that different developmental stages within insect species show distinct sensitivity towards insecticides, we used two approaches to each insecticide's exposure, particularly we obtained the $M$. domestica strains by exposure of adults in the first case (FipA and ChlA strains) and larvae in the second case (FipL and ChlL strains). According to the results, treatment of adult $M$. domestica with fipronil at a sublethal concentration in each subsequent generation for ten generations caused no changes in susceptibility to fipronil of adult flies while treatment of adult flies with chlorfenapyr in the same conditions led to the development the tolerance to chlorfenapyr in adults of the tenth generation. Moreover, adults of both $M$. domestica strains that were exposed to chlorfenapyr (i.e. ChlA and ChlL) displayed tolerance to this insecticide, independent of the approach used to insecticide exposure.

The life-history parameter study allows us to evaluate the total effect of an insecticide on an insect population (Xu et al., 2016). In our study the most general response to fipronil and chlorfenapyr exposure was changes in developmental parameters such as number of days from eggs to adults and the duration of the larva stage. In general, these parameters increased both when adults only were exposed to insecticides and when larvae only were exposed to insecticides.

\section{Table 6}

Weight of individuals at different developmental stages of insecticide-exposed and un-exposed (Lab) strains $(x \pm \mathrm{SD})$

\begin{tabular}{|c|c|c|c|c|}
\hline \multirow[b]{2}{*}{ Strain/generation } & \multicolumn{4}{|c|}{ Weight, mg } \\
\hline & larva & pupa & $\begin{array}{c}\text { three-five } \\
\text { days-old female }\end{array}$ & $\begin{array}{c}\text { three-five } \\
\text { days-old male }\end{array}$ \\
\hline $\mathrm{Lab}$ & $13.79 \pm 4.43$ & $13.21 \pm 3.56$ & $14.78 \pm 4.50$ & $8.74 \pm 2.01$ \\
\hline \multicolumn{5}{|c|}{ FipA strain } \\
\hline G2 & $13.42 \pm 4.80$ & $13.39 \pm 0.91$ & $11.63 \pm 2.47$ & $8.69 \pm 2.23$ \\
\hline G4 & $11.20 \pm 5.19$ & $13.01 \pm 1.74$ & $12.97 \pm 5.20$ & $6.91 \pm 1.17$ \\
\hline G6 & $13.80 \pm 6.86$ & $14.46 \pm 2.76$ & $12.25 \pm 4.08$ & $7.22 \pm 2.54$ \\
\hline G8 & $8.44 \pm 4.90$ & $14.48 \pm 0.46$ & $14.95 \pm 2.04$ & $9.40 \pm 1.91$ \\
\hline G10 & $15.33 \pm 0.84$ & $15.77 \pm 3.07$ & $13.70 \pm 2.48$ & $8.24 \pm 1.77$ \\
\hline $\mathrm{P}$ & 0.420 & 0.790 & 0.758 & 0.543 \\
\hline \multicolumn{5}{|c|}{ FipL strain } \\
\hline G2 & $9.52 \pm 2.40^{\#}$ & nd & $13.46 \pm 3.62^{\#}$ & $7.75 \pm 0.68^{\#}$ \\
\hline G4 & $16.02 \pm 6.19$ & $15.69 \pm 0.08$ & $18.60 \pm 2.62$ & $11.03 \pm 1.90$ \\
\hline G6 & $15.80 \pm 2.25$ & $13.39 \pm 1.56$ & $16.29 \pm 1.68$ & $8.42 \pm 0.64$ \\
\hline G8 & $16.77 \pm 0.87$ & $12.20 \pm 1.57$ & $16.94 \pm 1.50$ & $9.48 \pm 0.85$ \\
\hline G10 & $17.67 \pm 5.04$ & $15.99 \pm 1.14$ & $17.26 \pm 4.38$ & $9.91 \pm 2.20$ \\
\hline $\mathrm{P}$ & 0.039 & 0.446 & 0.655 & 0.407 \\
\hline \multicolumn{5}{|c|}{ ChlA-strain } \\
\hline $\mathrm{G} 2$ & $10.18 \pm 2.62$ & $10.56 \pm 1.31$ & $12.08 \pm 1.70$ & $7.42 \pm 0.98$ \\
\hline G4 & $9.90 \pm 3.74$ & $10.90 \pm 0.77$ & $13.55 \pm 1.81$ & $7.88 \pm 0.59$ \\
\hline G6 & $13.40 \pm 2.73$ & $13.95 \pm 1.10$ & $13.50 \pm 6.33$ & $8.13 \pm 2.61$ \\
\hline G8 & $14.43 \pm 6.03$ & $13.93 \pm 0.21$ & $12.45 \pm 5.45$ & $8.18 \pm 2.64$ \\
\hline G10 & $6.85 \pm 2.74$ & $13.45 \pm 1.85$ & $15.89 \pm 1.17$ & $9.06 \pm 1.46$ \\
\hline $\mathrm{P}$ & 0.021 & 0.452 & 0.896 & 0.886 \\
\hline \multicolumn{5}{|c|}{ ChlL strain } \\
\hline G2 & $9.26 \pm 3.20^{\#}$ & nd & $11.94 \pm 2.72^{\#}$ & $8.14 \pm 1.53^{\#}$ \\
\hline G4 & $10.99 \pm 3.70$ & nd & $15.95 \pm 5.43$ & $8.44 \pm 2.71$ \\
\hline G6 & $10.38 \pm 1.52$ & $16.55 \pm 1.41$ & $16.43 \pm 0.96$ & $9.36 \pm 2.49$ \\
\hline G8 & $14.06 \pm 2.99$ & $14.04 \pm 2.40$ & $13.35 \pm 3.76$ & $8.60 \pm 1.97$ \\
\hline G10 & $12.95 \pm 3.30$ & $12.60 \pm 1.46$ & $13.31 \pm 3.36$ & $7.09 \pm 1.60$ \\
\hline $\mathrm{P}$ & 0.223 & 0.530 & 0.730 & 0.703 \\
\hline
\end{tabular}

Notes: FipA - adults only were exposed to fipronil; FipL - larvae only were exposed to fipronil; $\mathrm{ChlA}$ - adults only were exposed to chlofenapyr; $\mathrm{ChlL}$ - larvae only were exposed to chlorfenapyr; $\mathrm{SD}$ - standard deviation; $\mathrm{P}$ - $\mathrm{p}$-value according to ANOVA test; ${ }^{\#}$-results from first and second generations together.

This observation agreed with results by other researchers which indicated that treatment with insecticides prolonged the insect development at the larval and pupal stages. For example, Xu et al. (2016) study showed that a sublethal dose of cyantraniliprole prolongs the duration of larval and pupal stages and decreases survivorship, longevity and fecundity of adults of the black cutworm Agrotis ipsilon Hufnagel, 1766 (Lepidoptera, Noctuidae). According to Ali et al. (2017) insecticide exposure of the parents significantly prolonged the development of the first generation in the rice pest Sogatella furcifera Horváth, 1899 (Hemiptera, Delphacidae). Rehan and Freed (2015) observed that sublethal concentrations $\mathrm{LC}_{30}$ of methoxyfenozide significantly prolonged the larval and pupal development time of Spodoptera litura Fabricius, 1775 (Lepidoptera, Noctiidae). As considered, 
the developmental delay of insecticide exposed populations might be a consequence of insufficient essential components for normal growth because more food resources have to be used for detoxification (Xu et al., 2016).

According to Xu et al. (2016) and Müller (2018) effects of insecticides at sublethal concentrations on reproduction and phenotype of targeted insects may differ because of different modes of action or application methods of insecticides. For example, Tang et al. (2015) indicated that the exposure of the parent generation to sublethal sulfoxaflor stimulated reproduction in the first progeny generation of the green peach aphid $M y$ zus persicae Sulzer, 1776 (Hemiptera, Aphididae). On the other hand, sublethal doses of insecticides cause reduction in fecundity of offspring. For example, Rehan \& Freed (2015) studies showed sublethal effects of methoxyfenozide on $S$. litura such as reduced number of eggs per female, egg hatching, and sex ratio. According to Tamilselvan et al. (2021), the fecundity of $\mathrm{F}_{1}$ generation was significantly lower in groups of diamondback moth, Plutella xylostella Linneaus, 1758 (Lepidoptera, Plutellidae), treated with insecticide spinosyn at sublethal concentrations $\left(\mathrm{LC}_{25}\right.$ and $\mathrm{LC}_{10}$ ) than the untreated control. Ali et al. (2017) observed that longevity and fecundity were decreased in the first generation $S$. furcifera as a result of parental exposure to insecticides. In our study, the exposure of $M$. domestica to fipronil and chlorfenapyr had no statistically significant impacts on adult fecundity. Although another study by Farooq \& Feed (2018) showed that fecundity decreased with the increased concentration of insecticide when adult house flies were provided sugar mixed with fipronil at $\mathrm{LC}_{10}, \mathrm{LC}_{30}$, and $\mathrm{LC}_{50}$ concentrations. Benelli et al. (2018) reported that the essential oil (at sublethal dose $\mathrm{LD}_{20}$ ) treatment on flies $M$. domestica led to a marked decrease in male and female longevity, as well as to a significant reduction in fecundity, fertility, and natality. The sublethal effects of insecticides may depend on concentrations. For example, Zhao et al. (2018) studied sublethal effects of chlorfenapyr on the life table parameters of Bradysia odoriphaga Yang and Zhang, 1985 (Diptera, Sciaridae) and observed that fecundity was significantly increased in the $\mathrm{LC}_{1}$ and $\mathrm{LC}_{20}$ treatment groups, whereas those of the $\mathrm{LC}_{50}$ treatment group were reduced significantly compared with the control. Also, in the present study, weights of individuals at each of the developmental stages did not vary statistically significantly in generations of the FipA, FipL, ChlA, and ChlL strains except larval weight in the tenth generation of the ChlA strain (Table 4). Baena-Díaz et al. (2018) showed that parental (mainly paternal) exposure of the dung beetle Euoniticellus intermedius Reiche, 1849 (Coleoptera, Scarabaeidae) to ivermectin had trans-generational effects on the morphological features of male offspring but did not affect offspring number, sex ratio or body size.

The mechanisms of parental transfer of environmental information to offspring are not as well known (Baena-Díaz et al., 2018; Bantz et al., 2018) as well as the exact mechanisms of chronic and sublethal effects of insecticides on life-history parameters of insects (Müller, 2018). One of the possible mechanisms is as follows: sublethal doses/concentrations of some neurotoxic insecticides change the reproductive behaviour of insects, which leads to changes in insect fecundity and fertility (Haynes, 1988; Delpuech \& Delahaye, 2013). Also, insecticides at sublethal doses/concentrations may impact insect populations by epigenetic changes in gametes resulting in differential gene expression in the offspring (Müller, 2018; Müller et al., 2019). Activation or inhibition of genes could be caused by such epigenetic mechanisms as DNA methylations, histone modifications, and heritable noncoding RNAs (Bantz et al., 2018). Recent transcriptomic studies that showed a multitude of modulated genes in insects under exposure to a sublethal dose of insecticides were described by Bantz et al. (2018). The authors noted that few studies have been done on epigenetics and inheritance involved in adaptive mechanisms after sublethal exposure of insects to pesticides (Bantz et al., 2018).

\section{Conclusion}

Insecticides not only kill susceptible individuals but also may change physiological and reproduction processes, developmental duration at any stage in surviving insects, and this way impact insect populations. In our study, fipronil exposure at the sublethal concentration in each generation did not affect the susceptibility of adult $M$. domestica (in the tenth generation) to fipronil but chlorfenapyr exposure under the same conditions resulted in a chlorfenapyr-tolerant tenth generation of flies. At the same time, the sublethal effects of both insecticides fipronil and chlorfenapyr affected the normal developmental stages of $M$. domestica and prolonged the larval stage duration and developmental time from egg to adult. However, this study only evaluated the effects of ten-generation exposure to sublethal concentrations of fipronil and chlorfenapyr on life-history parameters and weight of $M$. domestica. Further studies are needed to investigate the possible genetic variability in offspring in response to exposure of the parental generation to sublethal doses of these insecticides.

This work was funded by RFBR according to the research project No. 19-01600059.

Co-authors E. A. Silivanova and M. A. Levchenko are authors of the patent "Method of controlling flies in livestock buildings", RU, Pat. 2540553, and ASRIVEA is its holder.

\section{References}

Abbas, N., Shah, R. M., Shad, S. A., \& Azher, F. (2016). Dominant fitness costs of resistance to fipronil in Musca domestica Linnaeus (Diptera: Muscidae). Veterinary Parasitology, 226, 78-82.

Ali, E., Liao, X., Yang, P., Mao, K. K., Zhang, X. L., Shakeel, M., Salim, A. M. A., Wan H., \& Li J. (2017). Sublethal effects of buprofezin on development and reproduction in the white-backed planthopper, Sogatella furcifera (Hemiptera: Delphacidae). Scientific Reports, 7, 16913.

Ameen, A., Kaakeh, W., \& Bennett, G. W. (2000). Integration of chlorfenapyr into a management program for German cockroach (Dictyoptera: Blattellidae). Journal of Agricultural and Urban Entomology, 17, 135-142.

Baena-Díaz, F., Martínez-Morales, I., Gil-Pérez, Y., \& González-Tokman, D. (2018). Trans-generational effects of ivermectin exposure in dung beetles. Chemosphere, 202, 637-643.

Bantz, A., Camon, J., Froger, J. A., Goven, D., \& Raymond, V. (2018). Exposure to sublethal doses of insecticide and their effects on insects at cellular and physiological levels. Current Opinion in Insect Science, 30, 73-78.

Benelli, G., Pavela, R., Giordani, C., Casettari, L., Curzi, G., Cappellacci, L., Petrelli, R., \& Maggi, F. (2018). Acute and sub-lethal toxicity of eight essential oils of commercial interest against the filariasis mosquito Culex quinquefasciatus and the housefly Musca domestica. Industrial Crops and Products, 112, 668-680.

Buczkowski, G., Scharf, M. E., Ratliff, C. R., \& Bennett, G. W. (2005). Efficacy of simulated barrier treatments against laboratory colonies of pharaoh ant. Journal of Economic Entomology, 98, 485-492.

Byford, R. L., Craig, M. E., \& Crosby, B. L. (1992). A review of ectoparasites and their effect on cattle production. Journal of Animal Science, 70(2), 597-602.

Casida, J. E., \& Durkin, K. A. (2013). Neuroactive insecticides: Targets, selectivity, resistance, and secondary effects. Annual Review of Entomology, 58, 99-117.

de França, S. M., Breda, M. O., Barbosa, D. R. S., Araujo, A. M. N., \& Guedes, C. A. (2017). The sublethal effects of insecticides in insects. In: Shields, V. D. C. (Ed.). Biological control of pest and vector insects. IntechOpen, London.

Delpuech, J.-M., \& Delahaye, M. (2013). The sublethal effects of deltamethrin on Trichogramma behaviors during the exploitation of host patches. Science of the Total Environment, 447, 274-279.

Eremina, O. Y. (2017). Khlorfenapir - perspektivnyo insektitsid iz gruppy pirrolov dlya bor'by s rezistentnymi sinantropnymi nasekomymi [Chlorfenapyr - promising pyrrole insecticide for combating resistant synanthropic insects]. PestManagement, 101, 41-49 (in Russian).

Eremina, O. Y., Olekhnovich, E. I., Olifer, V. V., Ibragimkhalilova, I. V., Gevorkyan, I. S., Bendrysheva, S. N., \& Sarvin, B. A. (2016). Issledovanie rezistentnosti ryzhikh tarakanov $\mathrm{k}$ fipronilu [Investigation of Blattella germanica resistance to fipronil]. Dezinfektsionnoe Delo, 96(2), 33-42 (in Russian).

Farooq, M., \& Freed, S. (2018). Mortality, biological, and biochemical response of Musca domestica (Diptera: Muscidae) to selected insecticides. Journal of Entomological Science, 53, 27-45.

Förster, M., Klimpel, S., Mehlhom, H., Sievert, K., Messler, S., \& Pfeffer, K. (2007). Pilot study on synanthropic flies (e.g. Musca, Sarcophaga, Calliphora, Fannia, Lucilia, Stomoxys) as vectors of pathogenic microorganisms. Parasitology Research, 101, 243-246.

Guglielmone, A. A., Volpogni, M. M., Scherling, N., Cobeñas, M. M., Mangold, A. J., Anziani, O. S., Loppolo, M., \& Doscher, M. (2000). Chlorfenapyr ear tags to control Haematobia irritans (L.) (Diptera: Muscidae) on cattle. Veterinary Parasitology, 93(1), 77-82.

Haynes, K. F. (1988). Sublethal effects of neurotoxic insecticides on insect behavior. Annual Review Entomology. 33, 149-168.

Kozak, V. M., Romanenko, E. R., \& Brygadyrenko, V. V. (2020). Influence of herbicides, insecticides and fungicides on food consumption and body weight of Rossiulus kessleri (Diplopoda, Julidae). Biosystems Diversity, 28(3), 272-280. 
Kristensen, M., Jespersen, J. B., \& Knorr, M. (2004). Cross-resistance potential of fipronil in Musca domestica. Pest Management Science, 60, 894-900.

Lalouette, L., Pottier, M. A., Wycke, M. A., Boitard, C., Bozzolan, F., Maria, A., Demondion, E., Chertemps, T., Lucas, P., Renault, D., Maibeche, M., \& Siaussat, D. (2016). Unexpected effects of sublethal doses of insecticide on the peripheral olfactory response and sexual behavior in a pest insect. Environmental Science and Pollution Research, 23, 3073-3085.

Leontieva, T. L., Syrtlanova, L. A., \& Benkovskaya, G. V. (2016). Razvitie ustojchivosti $\mathrm{k}$ insektitsidam u koloradskogo zhuka na territorii Respubliki Bashkortostan [Development of Colorado potato beetle resistance to insecticides on the territory of the Republic of Bashkortostan]. Vestnik Bashkirskogo Gosudarstvennogo Agrarnogo Universiteta, 38(2), 11-14 (in Russian).

Levchenko, M. A., \& Silivanova, E. A. (2015). Effektivnost' insektitsidnykh primanochnykh sostavov dlya bor'by s mukhami [The effectiveness of insecticidal bait compositions for houseflies control]. Vestnik Veterinarii, 73(2), 23-26 (in Russian).

Müller, C. (2018). Impacts of sublethal insecticide exposure on insects - facts and knowledge gaps. Basic and Applied Ecology, 30, 1-10.

Müller, T., Römer, C. I., \& Müller, C. (2019). Parental sublethal insecticide exposure prolongs mating response and decreases reproductive output in offspring. Journal of Applied Ecology, 56, 1528-1537.

N'Guessan, R., Boko, P., Odjo, A., Akogbeto, M., Yates, A., \& Rowland, M. (2007) Chlorfenapyr: A pyrrole insecticide for the control of pyrethroid or DDT resistant Anopheles gambiae (Diptera: Culicidae) mosquitoes. Acta Tropica, 102, 69-78.

N'Guessan, R., Boko, P., Odjo, A., Knols, B., Akogbeto, M., \& Rowland, M. (2009). Control of pyrethroid-resistant Anopheles gambiae and Culex quinquefasciatus mosquitoes with chlorfenapyr in Benin. Tropical Medicine and International Health, 14, 389-395.

Qayyum, M. A., Wakil, W., Arif, M. J., Sahi, S. T., Saeed, N. A., \& Russell, D. A (2015). Multiple resistances against formulated organophosphates, pyrethroids, and newer-chemistry insecticides in populations of Helicoverpa armigera (Lepidoptera: Noctuidae) from Pakistan. Journal of Economic Entomology, 108(1) 286-293.

Rehan, A., \& Freed, S. (2015). Fitness cost of methoxyfenozide and the effects of its sublethal doses on development, reproduction, and survival of Spodoptera litura (Fabricius) (Lepidoptera: Noctuidae). Neotropical Entomology, 44(5), 513-520.
Romero, A., Potter, M. F., \& Haynes, K. F. (2010). Evaluation of chlorfenapyr for control of the bed bug, Cimex lectularius L. Pest Management Science, 66, $1243-1248$.

Rust, M. K., \& Saran, R. K. (2006). Toxicity, repellency, and transfer of chlorfenapyr against western subterranean termites (Isoptera: Rhinotermitidae). Journal of Economic Entomology, 99(3), 864-872.

Sparks, T. C., Crossthwaite, A. J., Nauen, R., Banba, S., Cordova, D., Earley, F., Ebbinghaus-Kintscher, U., Fujioka, S., Hirao, A., Karmon, D., Kennedy, R., Nakao, T., Popham, H. J. R., Salgado, V., Watson, G. B., Wedel, B. J., \& Wessels, F. J. (2020). Insecticides, biologics and nematicides: Updates to IRAC's mode of action classification - a tool for resistance management. Pesticide Biochemistry and Physiology, 167, 104587

Tamilselvan, R., Kennedy, J. S., \& Suganthi, A. (2021). Sublethal and transgenerational effects of spinetoram on the biological traits of Plutella xylostella (L.) (Lepidoptera: Plutellidae). Ecotoxicology, 30(4), 667-677.

Tang, Q., Xiang, M., Hu, H., An, C., \& Gao, X. (2015). Evaluation of sublethal effects of sulfoxaflor on the green peach aphid (Hemiptera: Aphididae) using life table parameters. Journal of Economic Entomology, 108(6), 2720-2728.

Ullah, S., Shah, R. M., \& Shad, S. A. (2016). Genetics, realized heritability and possible mechanism of chlorfenapyr resistance in Oxycarenus hyalinipennis (Lygaeidae: Hemiptera). Pesticide Biochemistry and Physiology, 133, 91-96.

Van Leeuwen, T., Stillatus, V., \& Tirry, L. (2004). Genetic analysis and cross-resistance spectrum of a laboratory-selected chlorfenapyr resistant strain of twospotted spider mite (Acari: Tetranychidae). Experimental and Applied Acarology, 32(4), 249-261.

Xu, C., Zhang, Z., Cui, K., Zhao, Y., Han, J., Liu, F., \& Mu, W. (2016). Effects of sublethal concentrations of cyantraniliprole on the development, fecundity and nutritional physiology of the black cutworm agrotisipsilon (Lepidoptera: Noctuidae). PLoS One, 11(6), e0156555.

Zhang, S., Zhang, X., Shen, J., Mao, K., You, H., \& Li, J. (2016). Susceptibility of field populations of the diamondback moth, Plutella xylostella, to a selection of insecticides in Central China. Pesticide Biochemistry and Physiology, 132, 38 - 46.

Zhao, Y., Wang, Q., Ding, J., Wang, Y., Zhang, Z., Liu, F., \& Mu, W. (2018). Sublethal effects of chlorfenapyr on the life table parameters, nutritional physiology and enzymatic properties of Bradysia odoriphaga (Diptera: Sciaridae). Pesticide Biochemistry and Physiology, 148, 93-102.

Zhu, F., Lavine, L., O’Neal, S., Lavine, M., Foss, C., \& Walsh, D. (2016). Insecticide resistance and management strategies in urban ecosystems. Insects, 7, 2. 